\title{
Water Interaction Differences Determine the Relative Energetic Stability of the Polyproline II Conformation of the Alanine Dipeptide in Aqueous Environments
}

\author{
Noemi G. Mirkin, Samuel Krimm \\ LSA Biophysics, University of Michigan, 930 N. University Ave., Ann Arbor, MI 48109-1055 \\ Received 23 February 2012; accepted 14 March 2012 \\ Published online 29 March 2012 in Wiley Online Library (wileyonlinelibrary.com). DOI 10.1002/bip.22064
}

\section{ABSTRACT:}

Although subsequent studies have provided extensive support for the 1968 Tiffany and Krimm proposal

(Biopolymers 6, 1379) that the polyproline II (PPII) conformation is a significant component of the structure of unordered polypeptide chains, two issues are still not fully resolved: the PPII persistence length in a chain and the source of its relative stability with respect to the $\beta$ conformation. We examine the latter question by studying the B97-D/6-31++ $G^{* *}$ energy, in the absence and presence of a reaction field, of the alanine dipeptide hydrated by various amounts of explicit waters and resolving this into its three components: the energies of the individual solvated peptides and water structures plus the interaction energy involving them. We find that the relative stability of the PPII conformation is determined mainly by the difference in the interaction energies of the water structures in the near-peptide layers. (1) 2012 Wiley Periodicals, Inc. Biopolymers 97: 789-794, 2012.

Keywords: peptides; water; polyproline II; conformation; ab initio; hydrogen bonds

This article was originally published online as an accepted preprint. The "Published Online" date corresponds to the preprint version. You can request a copy of the preprint by emailing the Biopolymers editorial office at biopolymers@wiley. com

Correspondence to: Samuel Krimm; e-mail: skrimm@umich.edu (C) 2012 Wiley Periodicals, Inc.

\section{INTRODUCTION}

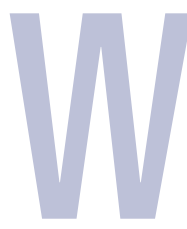

hile the correlations of the circular dichroism (CD) spectra of neutral poly-L-glutamic acid and poly-L-lysine with $\alpha$-helix or $\beta$-sheet conformations were relatively straightforward, the initial assignment of the essentially common spectra of their charged states, a strong negative band at $\sim 198 \mathrm{~nm}$ and a weak positive band at $\sim 218 \mathrm{~nm}$, was based on the assumption ${ }^{1,2}$ that these conformations would be representative of random coils, i.e., "disordered polypeptides." This view had been challenged by the Tiffany and Krimm (TK) observation that such CD spectra more likely derived from "significant portions of the chain (that) have a conformation close to that of the threefold helix of polyproline II," a proposal that was supported by their further experimental studies, ${ }^{5}$ including the effects of temperature ${ }^{6}$ and of denaturants such as urea and guanidine hydrochloride, ${ }^{7}$ and by related theoretical CD predictions. ${ }^{8,9}$ (As calculations had indicated possible variability in the helical symmetry with sequence length, ${ }^{10}$ this structure was designated an "extended-helix," although it is now commonly referred to as a PPII geometry.) It was also noted ${ }^{5}$ that the presence of such local order still allowed the chain "from a hydrodynamic point of view (to) have characteristics of a random coil." ${ }^{11}$ Although the TK assignment met with initial skepticism, ${ }^{12}$ a further evaluation concluded that a range of studies now furnished "strong evidence in favor of (this) proposal"13 and much subsequent research has supported this conclusion $^{14-18}$ including recent extended exciton-based theoretical CD studies. ${ }^{19,20}$

Despite this consensus, two significant structural issues still remain to be clarified: the number of consecutive PPII conformations in a peptide sequence and the source of its relative stability. With respect to the first issue, two opinions have emerged. The first envisioned a chain with "bends in it, the portion between bends being in the [PPII] conformation 
and containing a number of residues sufficient to give a characteristic CD spectrum." ${ }^{5}$ Of course, the bend regions in a sequence need not be fixed, allowing for a fluctuating molecular structure that would still give rise to overall random coil behavior in a polypeptide chain. This could account for the observed chain collapse in the much-studied XAO peptide $\left(\right.$ Ace $-(\text { Daba })_{2}-(\mathrm{Ala})_{7}-(\mathrm{Orn})_{2}-\mathrm{NH}_{2}$, Daba $=$ diaminobutyric acid, Orn = ornithine).$^{21-24}$ The second view interpreted the data on the seven-alanine-residue portion of XAO as being more consistent with a continuous PPII sequence, ${ }^{15,25,26}$ although the issue may still be open. ${ }^{16}$ It should be noted that quantitative conclusions that depend on molecular dynamics (MD) calculations using contemporary classical molecular mechanics (MM) force fields cannot avoid remaining open to question, since there is much evidence that such computational results vary significantly with the peptide and water force fields used. ${ }^{27-40}$ One reason for this problem (aside from occasional arbitrary assumptions such as constrained covalent bond lengths) is that these force fields only insist on structure and energy agreement (although even here evidence for the required relative accuracy is not established). This is a necessary but not a sufficient condition to guarantee the independent reproduction of physically accurate forces ${ }^{41,42}$ which are central to obtaining reliable MD simulations. The required correction to this deficiency, beyond incorporating polarization (which is only occasionally done), is the addition to the energy function of charge fluxes, i.e., changes in charge distribution with changes in geometry. ${ }^{43}$ This also assures vibrational spectroscopic accuracy, but this inclusion remains to be implemented in current force fields. Another reason for caution is that current MM functions are incomplete in their full physical representation of the hydrogen-bonding interactions, which is true of peptide $^{44}$ and especially of rigid water ${ }^{45,46}$ force fields. These deficiencies in current energy functions, leading to limited classical mechanical descriptions, thus cannot be fully relied on to reproduce all inherently-based quantum-mechanical properties of molecules. Comparisons of improved calculations with experimental results would also be aided by additional observational methods that can selectively characterize the full conformational distribution at each $\mathrm{C}^{\alpha}$ atom. Analysis of the relative intensity of the two characteristic bands in the CD spectrum, which according to theory is a function of the number of adjacent PPII conformations, ${ }^{19}$ may help in clarifying this issue. We have proposed a new technique that could provide this information through an analysis of the $\mathrm{C}^{\alpha} \mathrm{D}^{\alpha}$ stretch mode at individually isotopically substituted sites, ${ }^{47-50}$ this frequency being found to depend mainly on the $\varphi, \psi$ torsion angles at the site. We hope that this methodology can be implemented in studies of such systems.
The origin of the relative stability of the PPII conformation has been the subject of extensive studies, the contributions of steric, side chain, and solvation factors being particularly evaluated. ${ }^{51}$ While it is now generally believed that backbone solvation is involved ${ }^{25}$ (although some results discount this contribution ${ }^{52-54}$ ), and extensive experimental studies, including those on trialanine $e^{29,55-57}$ have enhanced this support, calculational efforts to define the nature of this interaction have not been conclusive. It was evident early on that the detailed impact of the solvent on the structure of the chain could only be properly modeled by studying the interactions of explicit water molecules with the backbone. This followed from calculations that the binding of explicit water to the imide groups of polyproline tends to rigidify this chain $^{58}$ and from preliminary indications that such binding to the general polypeptide chain would influence its structure. ${ }^{59}$ Tiffany and Krimm noted that "Water should also interact by hydrogen bonding to exposed carbonyl groups," although it was not yet clear "how solvent interaction may affect chain conformation." "11 Subsequent computational studies have been devoted to illuminating this issue, many involving investigations of a simple model molecule, the alanine dipeptide (ADP), $\mathrm{CH}_{3}-[\mathrm{CONH}]_{1}-\mathrm{CH}\left(\mathrm{CH}_{3}\right)-$ $[\mathrm{CONH}]_{2}-\mathrm{CH}_{3}$, as well as of longer peptide chains. Such structural efforts have focused on determinations of the relative free energies of ADP conformations in explicit water, based on Monte Carlo and MD computations ${ }^{60-69}$ using standard force fields for the peptide and water (although a qualified quantum molecular dynamics computation has been implemented ${ }^{70}$ ). A number of longer peptide systems have also been similarly analyzed. ${ }^{71-77}$ Although ab initio analysis alone does not provide a determination of the entropic component of the free energy, by avoiding assumptions of water rigidity and physically incomplete force fields it does give a more accurate account of the energetic and structural components of the solvation interaction, and there have been a few such studies of explicit hydration of the ADP. Based on B3LYP/6-31G* structures of isolated $\mathrm{ADP}^{78}$ and a sequence of force field plus ab initio minimizations of $\operatorname{ADP}\left(\mathrm{H}_{2} \mathrm{O}\right)_{4},{ }^{79}$ structures similar to PPII $\left(\varphi=-93.55^{\circ}, \psi=\right.$ $\left.127.62^{\circ}\right)$ and $\beta\left(\varphi=-150.88^{\circ}, \psi=116.47^{\circ}\right)$ forms were found with the energy of the $\beta$ being $1.886 \mathrm{kcal} / \mathrm{mol}$ higher than that of the PPII (the $\alpha_{\mathrm{R}}$ structure was still higher, at $2.465 \mathrm{kcal} / \mathrm{mol}$ ). This PPII structure was the basis for analyzing its NMR spectra ${ }^{80,81}$ and for calculating its vibrational absorption and vibrational circular dichroism spectra. ${ }^{82} \mathrm{~A}$ B3LYP/6-31+ $\mathrm{G}^{*}$ study of $\operatorname{ADP}\left(\mathrm{H}_{2} \mathrm{O}\right)_{4},{ }^{49}$ which focused on the effects of the different hydration structures on the $\mathrm{C}^{\alpha}-\mathrm{H}^{\alpha} \ldots \mathrm{O}$ (water) interactions, ${ }^{83}$ examined canonical $\beta$ $\left(\varphi=-134^{\circ}, \psi=145^{\circ}\right)$ and PPII $\left(\varphi=-75^{\circ}, \psi=145^{\circ}\right)$ 
conformations, optimizations of which resulted in the $\beta$ structure being more stable than PPII by $0.3 \mathrm{kcal} / \mathrm{mol}$. Interestingly, however, a comparable calculation of $\operatorname{ADP}\left(\mathrm{H}_{2} \mathrm{O}\right)_{6}$ resulted in PPII being more stable than $\beta$ by $1.0 \mathrm{kcal} / \mathrm{mol}$, indicating that the relative energies of solvated backbone conformations are influenced by the detailed nature of the interactions of water molecules hydrogen bonded to the peptide $\mathrm{C}=\mathrm{O}$ and $\mathrm{NH}$ groups and to each other. To begin a more in-depth ab initio investigation of the two major structural issues, we first follow up here on the above observation ${ }^{49}$ by examining the relative energies of the PPII and $\beta$-conformations of ADP solvated by varying amounts of water, in particular in $\operatorname{ADP}\left(\mathrm{H}_{2} \mathrm{O}\right)_{4}$, $\operatorname{ADP}\left(\mathrm{H}_{2} \mathrm{O}\right)_{6}$, and $\operatorname{ADP}\left(\mathrm{H}_{2} \mathrm{O}\right)_{12}$ (the relative energy of the $\alpha_{\mathrm{R}}$ conformation being significantly higher).

\section{COMPUTATIONAL METHODS}

Since the total energy of a given composite system is comprised of the sum of energies of its individual components plus the interaction energy between them, we can write the difference between PPII and $\beta$ energies of the solvated ADPs as

$$
\begin{aligned}
& \quad E\left(\mathrm{P}_{\mathrm{s}} \mathrm{w}_{\mathrm{n}}\right)-E\left(\beta_{\mathrm{s}} \mathrm{w}_{\mathrm{n}}\right)=E\left(\mathrm{P}_{\mathrm{s}}\right)-E\left(\beta_{\mathrm{s}}\right)+E_{\mathrm{P}}\left(\mathrm{w}_{\mathrm{n}}\right)-E_{\beta}\left(\mathrm{w}_{\mathrm{n}}\right) \\
& \quad+E(\mathrm{P})-E(\beta) \\
& \text { i.e., } \Delta E\left(\mathrm{P}_{\mathrm{s}} \beta_{\mathrm{s}} \mathrm{w}_{\mathrm{n}}\right)=\Delta E\left(\mathrm{P}_{\mathrm{s}} \beta_{\mathrm{s}}\right)+\Delta E_{\mathrm{P} \beta}\left(\mathrm{w}_{\mathrm{n}}\right)+\Delta E(\mathrm{P} \beta),
\end{aligned}
$$

where the $E\left(\mathrm{P}_{\mathrm{s}}\right)$ and $E\left(\beta_{\mathrm{s}}\right)$ represent the energies of the individual peptide structures in the solvated system, $E_{\mathrm{P}}\left(\mathrm{w}_{\mathrm{n}}\right)$ and $E_{\beta}\left(\mathrm{w}_{\mathrm{n}}\right)$ represent the energies of the $n$ individual water molecules in the cases of the indicated peptide conformations, and $E(\mathrm{P})$ and $E(\beta)$ represent the total intermolecular interaction energies of each system (which include water-water and water-peptide hydrogen bonds as well as all electrostatic interaction effects). Since all the other energies are determined directly by the ab initio calculations, $\Delta E(\mathrm{P} \beta)$ is readily obtained, as well as $\Delta E^{\prime}(\mathrm{P} \beta)$, the interaction energy difference per water molecule and per peptide group.

Optimizations were done for three classes of peptide structures, the above canonical conformations $\left(\beta\right.$ : $-134^{\circ}$, $145^{\circ}$; PPII: $\left.-75^{\circ}, 145^{\circ}\right)$, a slightly adjacent conformation suggested by recent studies of related peptides ${ }^{39,57,84}(\beta$ : $-140^{\circ}, 150^{\circ}$; PPII: $-70^{\circ}, 150^{\circ}$ ), and other nearby structures by varying $\varphi$ and $\psi$ by $\pm 5^{\circ}$ from their canonical values. Calculations were evaluated with Gaussian $09^{85}$ using DFT (B3LYP), dispersion-corrected DFT (B97-D), and secondorder perturbation MP2 with $6-31+\mathrm{G}^{*}, 6-31++\mathrm{G}^{* *}$, and aug-cc-pvtz basis sets, with and without a reaction field (polarized continuum model, PCM) surrounding the explicitly hydrated systems. The B97-D/6-31++ $\mathrm{G}^{* *}$ results were chosen as providing the optimum overall combination of
Table I B97-D/6-31 $++\mathrm{G}^{\star \star}$ Energies $^{\mathrm{a}}$ of Solvated Alanine Dipeptides

\begin{tabular}{cccccc}
\hline$n^{\mathrm{b}}$ & $\Delta E\left(P_{\mathrm{s}} \beta_{\mathrm{s}} w_{\mathrm{n}}\right)^{\mathrm{c}}$ & $\Delta E\left(P_{\mathrm{s}} \beta_{\mathrm{s}}\right)^{\mathrm{d}}$ & $\Delta E_{\mathrm{P} \beta}\left(w_{\mathrm{n}}\right)^{\mathrm{e}}$ & $\Delta E(P \beta)^{\mathrm{f}}$ & $\Delta E^{\prime}(P \beta)^{\mathrm{g}}$ \\
\hline 0 & & & & & \\
4 & -0.19 & 0.68 & 0.05 & -0.64 & -0.08 \\
& -0.04 & 0.30 & -0.01 & -0.33 & -0.04 \\
6 & -1.79 & 1.88 & 0.04 & -3.71 & -0.31 \\
& -0.67 & 1.44 & -0.21 & -1.90 & -0.16 \\
12 & -6.63 & 1.98 & 0.02 & -8.63 & -0.36 \\
& -5.76 & 1.77 & 0.52 & -8.05 & -0.34 \\
\hline
\end{tabular}

\footnotetext{
${ }^{\mathrm{a}}$ In kcal $/ \mathrm{mol}$, for canonical structures $\left(\beta:-134^{\circ}, 145^{\circ}\right.$; PPII: $\left.-75^{\circ}, 145^{\circ}\right)$.

${ }^{\mathrm{b}}$ Number of water molecules in $\operatorname{ADP}\left(\mathrm{H}_{2} \mathrm{O}\right)_{n}$.

${ }^{c}$ Energy difference between PPII and $\beta$ solvated systems consisting of the peptide plus $n$ water molecules. Second entry: with PCM.

${ }^{\mathrm{d}}$ Energy difference between individual PPII and $\beta$ structures in the solvated systems.

${ }^{\mathrm{e}}$ Energy difference between $n$ water molecules associated with PPII and $\beta$ conformers.

${ }^{\mathrm{f}}$ Interaction energy difference between PPII and $\beta$ systems.

${ }^{\mathrm{g}}$ Interaction energy difference per water molecule and per peptide
} group.

hydrogen-bonding and dispersion accuracy ${ }^{86,87}$ (the 6$31++G^{* *}$ basis set gives essentially the same quantitative results as the aug-cc-pvtz set). The starting water positions for $\operatorname{ADP}\left(\mathrm{H}_{2} \mathrm{O}\right)_{6}$ were determined by adding a second water to hydrogen bond to each peptide oxygen of the optimized $\operatorname{ADP}\left(\mathrm{H}_{2} \mathrm{O}\right)_{4}$ structure; the starting water positions for $\operatorname{ADP}\left(\mathrm{H}_{2} \mathrm{O}\right)_{12}$ were determined by placing three waters in the second-layer positions of the optimized $\operatorname{ADP}\left(\mathrm{H}_{2} \mathrm{O}\right)_{6}$ structure. Full minimizations of these systems were then done with the only constraints being the $\varphi, \psi$ of the chosen peptide structures. The energies of the peptide and water components were obtained from their actual structures in the solvated system optimizations. As noted above, the values of $\Delta E(\mathrm{P} \beta)$ and $\Delta E^{\prime}(\mathrm{P} \beta)$ follow immediately.

\section{RESULTS AND DISCUSSION}

The values of all the quantities in Equation (1) for canonical $\operatorname{ADP}\left(\mathrm{H}_{2} \mathrm{O}\right)_{n}$ with $n=0,4,6$, and 12 are presented in Table I. It should be recalled that, since all energies are negative, a negative value of the difference between PPII and $\beta$ quantities signifies that the energy in the PPII state is lower than that in the $\beta$ state, and vice versa. The structures of the PPII and $\beta$ forms of $\mathrm{ADP}\left(\mathrm{H}_{2} \mathrm{O}\right)_{12}(\mathrm{PCM})$ are shown in Figure 1.

The salient result from these calculations is that, despite the negative total $\Delta E\left(\mathrm{P}_{\mathrm{s}} \beta_{\mathrm{s}} \mathrm{w}_{\mathrm{n}}\right)$ that favors the PPII conformation in the complete solvated systems, $\Delta E\left(\mathrm{P}_{\mathrm{s}} \beta_{\mathrm{s}}\right)$ is positive, 1.88 and $1.98 \mathrm{kcal} / \mathrm{mol}$ for $n=6$ and 12 , respectively, for the non-PCM results, and thus the $\beta$-conformation of the peptide itself in the solvated state is intrinsically more stable 

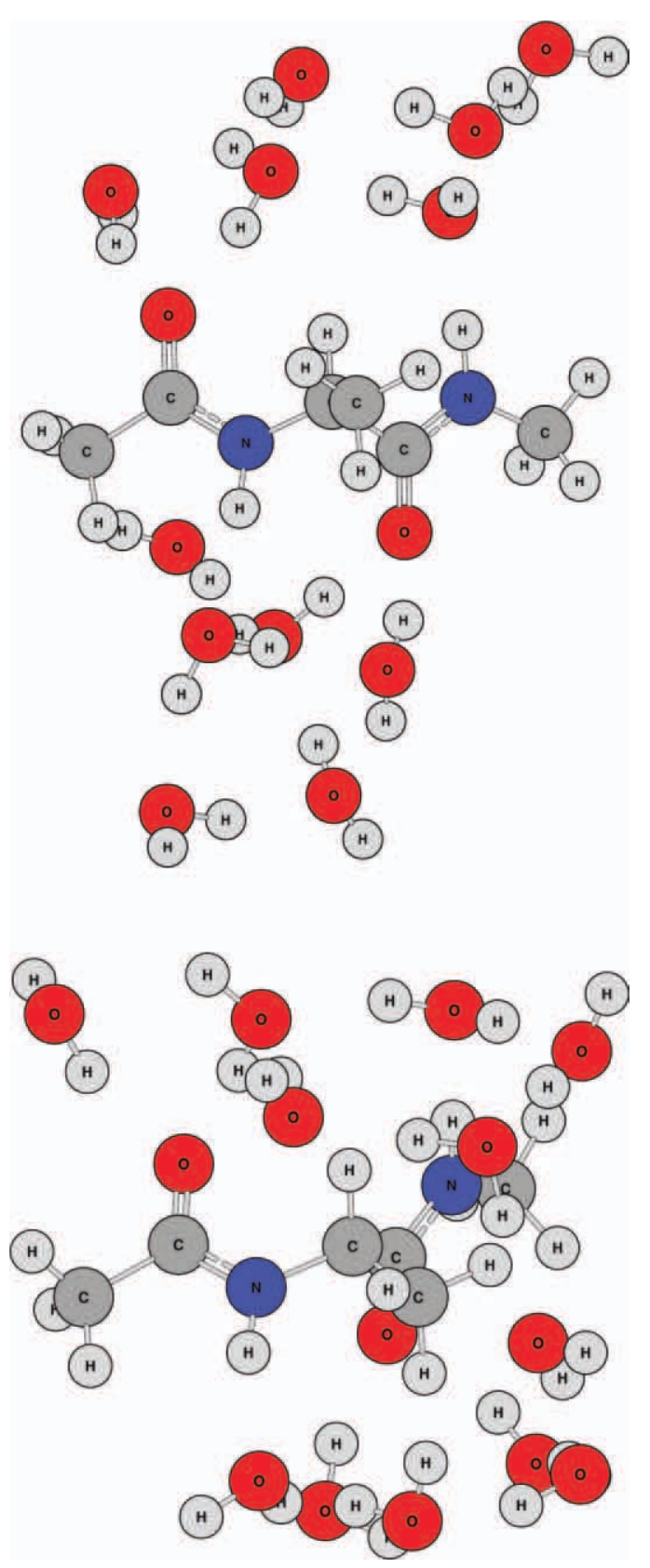

FIGURE 1 Alanine dipeptide hydrated with 12 water molecules and optimized at the B97-D/6-31++ $\mathrm{G}^{* *}$ level in a polarized continuum model reaction field in the beta (top: $-134^{\circ}, 145^{\circ}$ ) and polyproline II (bottom: $-75^{\circ}, 145^{\circ}$ ) conformations.

than the PPII conformation (as is true in the isolated state). However, the interaction energy differences associated with the waters, $\Delta \mathrm{E}(\mathrm{P} \beta)$, are dominantly negative, -3.71 and $-8.63 \mathrm{kcal} / \mathrm{mol}$, respectively, and thus the total favors the PPII structure, by -1.79 and $-6.63 \mathrm{kcal} / \mathrm{mol}$, respectively. Despite the large difference in the latter values, associated with the significant difference in the number of water molecules, the interaction energy differences per water and per peptide, $\Delta \mathrm{E}^{\prime}(\mathrm{P} \beta)$, are substantially the same, -0.31 and $-0.36 \mathrm{kcal} / \mathrm{mol}$, respectively. The energy differences for all the waters, $\Delta \mathrm{E}_{\mathrm{P} \beta}\left(\mathrm{w}_{\mathrm{n}}\right)$, are minimal. These properties are much different for $n=4$ : $\Delta E\left(\mathrm{P}_{\mathrm{s}} \beta_{\mathrm{s}} \mathrm{w}_{\mathrm{n}}\right)=-0.19 \mathrm{kcal} / \mathrm{mol}, \Delta \mathrm{E}\left(\mathrm{P}_{\mathrm{s}} \beta_{\mathrm{s}}\right)$ is less positive $(0.40$ $\mathrm{kcal} / \mathrm{mol})$ than in the isolated state, and $\Delta \mathrm{E}^{\prime}(\mathrm{P} \beta)$ is much smaller, $-0.08 \mathrm{kcal} / \mathrm{mol}$, demonstrating the importance of at least having complete first-layer water-peptide interactions, which are lacking in this structure (since each peptide oxygen is not hydrogen bonded to two waters).

The addition of the PCM treatment to the explicitly hydrated ADP system produces changes in the magnitudes of the PPII preferences, $\Delta E\left(\mathrm{P}_{\mathrm{s}} \beta_{\mathrm{s}} \mathrm{w}_{\mathrm{n}}\right)$, that follow mainly from the changes in the interaction energy difference per water and per peptide, $\Delta \mathrm{E}^{\prime}(\mathrm{P} \beta)$, maximally for $n=4$ and 6 and minimally for $n=12$ : for $n=6$ from -1.79 to $-0.67 \mathrm{kcal} / \mathrm{mol}$ for the first quantity and from -0.31 to $-0.16 \mathrm{kcal} / \mathrm{mol}$ for the second quantity and for $n=12$ from -6.63 to -5.76 for the first quantity and from -0.36 to $-0.34 \mathrm{kcal} / \mathrm{mol}$ for the second quantity. The significantly different results for $n=6$ and the similar results for $n=12$ indicate that the reaction field effects of more distant waters are very sensitive to the specific water structures in the inner layers, and that the inclusion of at least a double layer of peptide waters in restricted calculations is necessary to capture the main quantitative effects of solvation.

The results for the different selected peptide conformations reflect the specific shapes of the respective energy basins, but in this case the variations show no influence on the qualitative character of the PPII preference and only small differences in the quantitative values: for $n=12$, for the $\beta$ : $-140^{\circ}, 150^{\circ}$ and PPII: $-70^{\circ}, 150^{\circ}$ structures $\Delta E\left(\mathrm{P}_{\mathrm{s}} \beta_{\mathrm{s}} \mathrm{w}_{\mathrm{n}}\right)=-6.28(-5.71 \mathrm{PCM}) \mathrm{kcal} / \mathrm{mol}$, and for each structure of lowest energy in this group compared to the canonical $\left(\beta:-130^{\circ}, 140^{\circ}\right.$ and PPII: $\left.-80^{\circ}, 140^{\circ}\right) \Delta E\left(\mathrm{P}_{\mathrm{s}} \beta_{\mathrm{s}} \mathrm{w}_{\mathrm{n}}\right)=$ -6.77 ( $-5.94 \mathrm{PCM}) \mathrm{kcal} / \mathrm{mol}$.

The answer, then, to the question about the relative energetic stability of the PPII over the $\beta$-conformation in the $\mathrm{ADP}$ is that it is determined by the different energetic interactions, $\Delta E(\mathrm{P} \beta)$, associated with the specific configurations of the nearby solvating water molecules. The topological difference in water structures can be seen in Figure 1, and even though the combined polarization effects for each peptide conformation are likely to be similar, their hydrogen bonding properties are distinguishingly different: the average of the lengths of the water-peptide bonds is $0.022 \AA$ (PCM) smaller for the PPII conformation than for the $\beta$-conformation and the average for the comparable water-water hydrogen bonds is $0.055 \AA$, again in favor of PPII. This corresponds to an explicitly favorable PPII hydrogen bond energy contribution to $\Delta E^{\prime}(\mathrm{P} \beta)$. For the more distant waters represented by the PCM reaction field, with their greater and 
more equivalent mobility, the energy difference obviously tends to zero. This negative interaction energy difference, $\Delta \mathrm{E}(\mathrm{P} \beta)$, overcomes the positive peptide energy difference to determine the negative $\Delta E\left(\mathrm{P}_{s} \beta_{\mathrm{s}} \mathrm{w}_{\mathrm{n}}\right)$, and thus the degree of PPII stabilization. Since it can be expected that in more general systems such water structures will depend sensitively on the specific features of the peptide composition, a similar dependence applies to $\Delta E\left(\mathrm{P}_{\mathrm{s}} \beta_{\mathrm{s}} \mathrm{w}_{\mathrm{n}}\right)$. It is also clear that the accurate reproduction of such structural properties by MM simulations must depend on the ability of the energy functions to quantitatively reproduce all the physically relevant water and peptide interactions.

Of course, the complete quantitative answer to the source of PPII stability at non-zero temperatures resides in the free energy, which is also determined by the entropy difference between the two solvated systems, since $\Delta G\left(\mathrm{P}_{\mathrm{s}} \beta_{\mathrm{s}} \mathrm{w}_{\mathrm{n}}\right)=$ $\Delta H\left(\mathrm{P}_{\mathrm{s}} \beta_{\mathrm{s}} \mathrm{w}_{\mathrm{n}}\right)-T \Delta S\left(\mathrm{P}_{\mathrm{s}} \beta_{\mathrm{s}} \mathrm{w}_{\mathrm{n}}\right)$, where the enthalpy, $\Delta H$, follows $\Delta E$. Although not determined by the present calculations, the sign of $\Delta S\left(\mathrm{P}_{\mathrm{s}} \beta_{\mathrm{s}} \mathrm{w}_{\mathrm{n}}\right)$ can be obtained from the TK experimental study of the effect of temperature on the CD spectra of poly-Lglutamic acid and poly-L-lysine ${ }^{6}$ (subsequently reproduced in these polymers ${ }^{88}$ and in shorter peptides ${ }^{56,89,90}$ ): between 55 and $5^{\circ} \mathrm{C}$ the strong negative band at $\sim 198 \mathrm{~nm}$ increases in its intensity by a factor of $\sim 2$. This was interpreted as being "in agreement with an assignment to a more regular, viz., the [PPII] structure," ${ }^{6}$ which would now be described as an increase in the number of contiguous PPII conformations. ${ }^{19}$ Increasing temperature thus disfavors the PPII conformation, that is, results in a decreasingly negative $\Delta G\left(\mathrm{P}_{\mathrm{s}} \beta_{\mathrm{s}} \mathrm{w}_{\mathrm{n}}\right)$, and, for an unchanging $\Delta E\left(\mathrm{P}_{\mathrm{s}} \beta_{\mathrm{s}}\right)$, indicates that $\Delta S\left(\mathrm{P}_{\mathrm{s}} \beta_{\mathrm{s}} \mathrm{w}_{\mathrm{n}}\right)$ is negative (consistent with the same result found for trialanine ${ }^{89}$ ). This supports previous conclusions that $\beta$-like conformations are favored over PPII at higher temperatures. ${ }^{57,89,90}$

\section{CONCLUSIONS}

While there has been a broad consensus that solvation is involved in the preference for the local PPII conformation in the structure of the unordered peptide chain, the specific nature of this relative stability has remained unclear. Our analysis of the components of the energy of the alanine dipeptide hydrated with increasing numbers of explicit water molecules shows that the controlling factor is the difference in interaction energies associated with the distinctively different essentially double-layer water structures of the $\beta$ and PPII peptide conformations. In this connection, it is important that at least such a double water layer be included as a minimal structural feature of the calculations and that a reaction field treatment be part of the quantitative analysis. These insights make it clear that such a relative stability is likely to be sensi- tive to such factors as the length and the sequence of peptide conformations, as well as on the nature of the side chains. $^{50,91}$ We are currently investigating the influences of these factors on the energetics. The generally observed temperature dependence of the circular dichroism spectra of peptide systems indicates that the entropic component of the free energy difference will favor the $\beta$-conformation as the temperature increases. The reliable prediction of these free energy properties by MM simulations will depend on accurate quantitative reproduction of all such characteristics, which clearly must depend on the ability of the force fields to correctly reproduce all the physically relevant water and peptide interactions, i.e., "to get the physics right."

\section{REFERENCES}

1. Tanford, C.; Kawahara, K.; Lapanje, S. J Biol Chem 1966, 241, 1921-1923.

2. Flory, P. J. Statistical Mechanics of Chain Molecules; John Wiley and Sons: New York, 1969.

3. Greenfield, N.; Fasman, G. D. Biochemistry 1969, 8, 4108-4116.

4. Tiffany, M. L.; Krimm, S. Biopolymers 1968, 6, 1379-1381.

5. Tiffany, M. L.; Krimm, S. Biopolymers 1969, 8, 347-359.

6. Tiffany, M. L.; Krimm, S. Biopolymers 1972, 11, 2309-2316.

7. Tiffany, M. L.; Krimm, S. Biopolymers 1973, 12, 575-587.

8. Ronish, E. W.; Krimm, S. Biopolymers 1972, 11, 1919-1928.

9. Ronish, E. W.; Krimm, S. Biopolymers 1974, 13, 1635-1651.

10. Krimm, S.; Mark, J. E. Proc Natl Acad Sci USA 1969, 60, 1122-1129.

11. Krimm, S.; Tiffany, M. L. Isr J Chem 1974, 12, 189-200.

12. Woody, R. W. J Polym Sci Macromol Rev 1977, 12, 181-320.

13. Woody, R. W. Adv. Biophys Chem 1992, 2, 37-79.

14. Shi, Z.; Woody, R. W.; Kallenbach, N. R. Adv Protein Chem 2002, 62, 163-240.

15. Shi, Z.; Chen, K.; Liu, Z.; Kallenbach, N. R. Chem Rev 2006, 106, 1877-1897.

16. Chen. K.; Liu, Z.; Bracken, W. C.; Lu, M.; Kallenbach, N. R. In Unfolded Proteins: From Denatured to Intrinsically Disordered; Creamer, T. P., Eds.; Nova Science Publishers, Hauppauge, N.Y. 2008; pp 71-99.

17. Chellgren, V. M.; Chellgren, B. W.; Creamer, T. P. In Unfolded Proteins: From Denatured to Intrinsically Disordered; Creamer, T. P., Eds.; Nova Science Publishers, 2008; pp 143-167.

18. Gaigeot, M.-P. Phys Chem Chem Phys 2010, 12, 10198-10209.

19. Woody, R. W. J Am Chem Soc 2009, 131, 8234-8245.

20. Woody, R. W. Chirality 2010, 22, E22-E29.

21. Zagrovic, B.; Lipfert, J.; Sorin, E. J.; Millett, I. S.; van Gunsteren, W. F.; Doniach, S.; Pande, V. S. Proc Natl Acad Sci USA 2005, 102, 11698-11703.

22. Makowska, J.; Rodziewicz-Motowidlo, S.; Baginska, K.; Vila, J. A.; Liwo, A.; Chmurzynski, L.; Scheraga, H. A. Proc Natl Acad Sci USA 2006, 103, 1744-1749.

23. Makowska, J.; Rodziewicz-Motowidlo, S.; Baginska, K.; Makowski, M.; Vila, J. A.; Liwo, A.; Chmurzynski, L.; Scheraga, H. A. Biophys J 2007, 92, 2904-2917.

24. Makowska, J.; Baginska, K.; Skwierawska, A.; Liwo, A.; Chmurzynski, L.; Scheraga, H. A. Biopolymers (Pept Sci) 2008, 90, 772-782. 
25. Shi, Z.; Olson, C. A.; Rose, G. D.; Baldwin, R. L.; Kallenbach, N. R. Proc Natl Acad Sci USA 2002, 99, 9190-9195.

26. Chen, K.; Liu, Z.; Zhou, C.; Bracken, W. C.; Kallenbach, N. R. Angew Chem Int Ed 2007, 46, 9036-9039.

27. Beachy, M. D.; Chasman, D.; Murphy, R. B.; Halgren, T. A.; Friesner, R. A. J Am Chem Soc 1997, 119, 5908-5920.

28. Hu, H.; Elstner, M.; Hermans, J. Proteins 2003, 50, 451-463.

29. Mu, Y.; Kosov, D. S.; Stock, G. J Phys Chem B 2003, 107, 5064-5073.

30. Yoda, T.; Sugita, Y.; Okamoto, Y. Chem Phys 2004, 307, 269-283.

31. Gnankaran, S.; Garcia, A. Proteins 2005, 59, 773-782.

32. Kwac, K.; Lee, K. -K.; Han, J. B.; Oh, K. -I.; Cho, M. J Chem Phys 2008, 128, 105-106.

33. Aliev, A. E.; Courtier-Murias, D. J Phys Chem B 2010, 114, 12358-12375.

34. Hu, Z.; Jiang, J. J Comput Chem 2010, 31, 371-380.

35. Mittal, J.; Best, R. B. Biophys J 2010, 99, L26-L28.

36. Florova, P.; Sklenovsky, P.; Banas, P.; Otyepka, M. J Chem Theory Comput 2010, 6, 3569-3579.

37. Cerutti, D. S.; Freddolino, P. L.; Duke, Jr., R. E.; Case, D. A. J Phys Chem B 2010, 114, 12811-12824.

38. Piana, S.; Lindorff-Larsen, K.; Shaw, D. E. Biophys J 2011, 100, L47-L49.

39. Nerenberg, P. S.; Head-Gordon, T. J Chem Theory Comput 2011, 7, 1220-1230.

40. Patapati, K. K.; Glykos, N. M. Biophys J 2011, 101, 1766-1771.

41. Feynman, R. P. Phys Rev 1939, 56, 340-343.

42. Palmo, K.; Mannfors, B.; Mirkin, N. G.; Krimm, S. Chem Phys Lett 2006, 429, 628-632.

43. Palmo, K.; Mannfors, B.; Mirkin, N. G.; Krimm, S. Biopolymers 2003, 68, 383-394.

44. Hermans, J. Adv Protein Chem 2006, 72, 105-119.

45. Mannfors, B.; Palmo, K.; Krimm, S. J Phys Chem A 2008, 112, 12667-12678.

46. Li, X.-Z.; Walker, B.; Michaelides, A. Proc Natl Acad Sci USA 2011, 108, 6369-6373.

47. Mirkin, N. G.; Krimm, S. J Phys Chem A 2004, 108, 10923 10924.

48. Mirkin, N. G.; Krimm, S. J Phys Chem A 2007, 111, 5300-5303.

49. Mirkin, N. G.; Krimm, S. Biopolymers 2009, 91, 791-800.

50. Mirkin, N. G.; Krimm, S. Biopolymers 2010, 93, 1065-1071.

51. Creamer, T. P.; Campbell, M. N. Adv Protein Chem 2002, 62, 263-282.

52. Pappu, R. V.; Rose, G. D. Protein Sci 2002, 11, 2437-2455.

53. Drozdov, A. N.; Grossfield, A.; Pappu, R. V. J Am Chem Soc 2004, 126, 2574-2581.

54. Law, P. H.; Daggett, V. Prot Eng, Des Sel 2010, 23, 27-33.

55. Woutersen, S.; Hamm, P. J Phys Chem B 2000, 104, 11316-11320.

56. Oh, K.-I.; Lee, K.-K.; Park, E.-U.; Yoo, D.-G.; Hwang, G.-S.; Cho, M. Chirality 2010, 22, E186-E201.

57. Toal, S.; Amidi, O.; Schweitzer-Stenner, R. J Am Chem Soc 2011, 133, 12728-12739.

58. Krimm, S.; Venkatachalam, C. M. Proc Natl Acad Sci USA 1971, 68, 2468-2471.

59. Venkatachalam, C. M.; Krimm, S. In Conformation of Biological Molecules and Polymers; Bergmann, E. D.; Pullman, B., Eds.; Academic Press: New York, 1973; pp 141-154

60. Rossky, P. J.; Karplus, M. J Am Chem Soc 1979, 101, 1913-1937.
61. Hagler, A. T.; Osguthorpe, D. J.; Robson, B. Science 1980, 208 , 599-601.

62. Mezei, M.; Mehrota, P. K.; Beveridge, D. L. J Am Chem Soc 1985, 107, 2239-2245.

63. Pettitt, B. M.; Karplus, M. Chem Phys Lett 1985, 121, 194-201.

64. Anderson, A. G.; Hermans, J. Proteins 1988, 3, 262-265.

65. Tobias, D. J.; Brooks III, C. L. J Phys Chem 1992, 96, 3864-3870.

66. Smith, P. E. J Chem Phys 1999, 111, 5568-5579.

67. Seabra, G. de M.; Walker, R. C.; Elstner, M.; Case, D. A.; Roitberg, A. E. Phys Chem A 2007, 111, 5655-5664.

68. Ishizuka, R.; Huber, G. A.; McCammon, J. A. J Phys Chem Lett 2010, 1, 2279-2283.

69. Cruz, V.; Ramos, J.; Martinez-Salazar, J. J Phys Chem B 2011, 115, 4880-4886.

70. Gaigeot, M.-P. J Phys Chem B 2009, 113, 10059-10062.

71. Sreerama, N.; Woody, R.W. Proteins 1999, 36, 400-406.

72. Garcia, A. E. Polymer 2004, 45, 669-676.

73. Mezei, M.; Fleming, P. J.; Srinivasan, R.; Rose, G. D. Proteins 2004, 55, 502-507.

74. Kentsis, A.; Mezei, M.; Gindin, T.; Osman, R. Proteins 2004, 55, 493-501.

75. Kentsis, A.; Mezei, M.; Osman, R. Proteins 2005, 61, 769-776.

76. Sorin, E. J.; Rhee, Y. M.; Shirts, M. R.; Pande, V. S. J Mol Biol 2006, 356, 248-256.

77. Czapiewski, D.; Zielkiewicz, J. J Phys Chem B 2010, 114, 4536-4550.

78. Jalkanen K. J.; Suhai, S. Chem Phys 1996, 208, 81-116.

79. Han, W.-G.; Jalkanen, K. J.; Elstner, M.; Suhai, S. J Phys Chem B 1998, 102, 2587-2602.

80. Poon, C.-D.; Samulski, E.T.; Weise, C. F.; Weisshaar, J. C. J Am Chem Soc 2000, 122, 5642-5643.

81. Weise, C. F.; Weisshaar, J. C. J Phys Chem B 2003, 107, 3265-3277.

82. Jalkanen, K. J.; Degtyarenko, I. M.; Nieminen, R. M.; Cao, X.; Nafie, L. A.; Zhu, F.; Barron, L. D. Theor Chem Acc 2008, 119, 191-210.

83. Mirkin N. G.; Krimm, S. J Phys Chem B 2008, 112, 15267-15268.

84. Avbelj, F.; Baldwin, R. L. Proc Natl Acad Sci USA 2003, 100, 5742-5747.

85. Gaussian 09, Revision A.2, Frisch, M. J., et al., Gaussian, Wallingford CT, 2009.

86. Anthony, J.; Grimme, S. Phys Chem Chem Phys 2006, 8, 5287-5293.

87. Bouteiller, Y.; Poully, J. C.; Desfrançois, C.; Grégoire, G. J Phys Chem A 2009, 113, 6301-6307.

88. Drake, A. F.; Siligardi, G.; Gibbons, W. A. Biophys Chem 1988, 31, 143-146.

89. Eker, F.; Griebenow, K.; Schweitzer-Stenner, R. J Am Chem Soc 2003, 125, 8178-8185.

90. Chen, K.; Liu, Z.; Kallenbach, N. R. Proc Natl Acad Sci USA 2004, 101, 15352-15357.

91. He, L.; Navarro, A. E.; Shi, Z.; Kallenbach, N. R. J Am Chem Soc 2012, 134, 1571-1576.

92. Nicholls, A. J Comput Aided Mol Des 2011, DOI 10.1007/ s10822-011-9520-3.

Reviewing Editor: J. Andrew McCammon 